The impact of monitoring and sanctioning and perceived loafing towards revenge motive and tendency to commit counterproductive work behaviors within the academic workplace

$\mathrm{Hu}$, Yueh-Luen

Department of Education, National Chengchi University, Taiwan (joyhu@nccu.edu.tw)

Hung, Chao-Hsiang

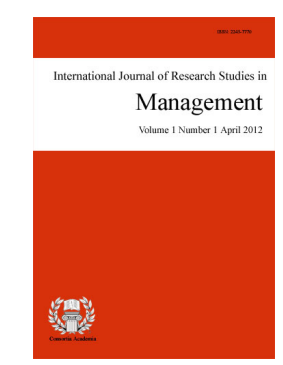

ISSN: $2243-7770$ Online ISSN: 2243-7789

OPEN ACCESS

Department of Education, National Chengchi University, Taiwan (aka0518@gmail.com)

Ching, Gregory S.

Graduate Institute of Educational Leadership and Development, Fu Jen Catholic University, Taiwan (gregoryching@yahoo.com;094478@mail.fiu.edu.tw)

\title{
Abstract
}

Within the actual practical day to day activities, even within an academic setting, counterproductive work behaviors (CWB) exist. Taking note of the harm that CWBs are able to induce on both individuals and organizations, it would seem appropriate that antecedents of CWBs be clearly understood. More so within an academic setting, wherein there is a system of monitoring and sanctioning in placed, CWBs should be kept to a minimum. However, this is not the case, previous CWB studies suggests a moderate occurrence of deviant behaviors within academic institutions. To better understand this phenomenon, the current study hypothesized that perceived loafing (PL) of peers is mediated by an individual's revenge motive (RM), which in turn affects the prevalence of CWBs. Furthermore, the current study also investigates the role of monitoring and sanctioning (MAS) towards an individual's tendency to loaf. Participants are 935 teachers employed during the 2015 school year in Taiwan. Survey items include the Mulvey and Klein's (1998) loafing scale, Jones' (2009) revenge motive scale, Fine, Horowitz, Weigler, and Basis's (2010) monitoring and sanctioning scale, and Hu, Hung, and Ching's (2015) CWB Taiwan scale (CWB-T). Using the statistical method of structured equation modelling (SEM), results suggest that PL has an increasing effect on both RM and CWB-T. In addition, RM seems to act as a mediator between PL and CWB-T, while MAS exhibits a decreasing effect on PL. In sum, findings suggest that in order for academic institutions to minimize the occurrence of CWBs, appropriate monitoring and sanctioning must be implemented.

Keywords: work attitude; teacher; deviant behavior; loafing; monitoring; sanctioning; counterproductive work behavior; revenge motive; mediation 


\section{The impact of monitoring and sanctioning and perceived loafing towards revenge motive and tendency to commit counterproductive work behaviors within the academic workplace}

\section{Introduction}

Studies has proven that a healthy workplace can lead to increase productivity (Danna \& Griffin, 1999). A healthy workplace would mean that the organization practices and promotes work-life balance, employee growth and development, health and safety, recognition, and employee involvement (Grawitch, Gottschalk, \& Munz, 2006). More important is the sense of equality within the workplace (Cornelius, 2002). However, this sense of equal treatment is tested, when the honest employee experiences coworkers getting away with loafing (Mulvey \& Klein, 1998). Recent studies have categorized loafing as a type of deviant or counterproductive work behavior (CWB) (Ahmadi, Bagheri, Ebrahimi, Rokni, \& Safari-Kahreh, 2011), wherein its effect can be damaging to the organization (Semmer, Tschan, Meier, Facchin, \& Jacobshagen, 2009).

Similar to other workplace, CWB exists even within academic institutions (Fox, Spector, \& Miles, 2001; Fox \& Stallworth, 2010; Y.-L. Hu, Hung, \& Ching, 2015; Salami, 2010). One might thought that the implementation of a school wide positive behavior support (Sugai \& Horner, 2008; Sugai \& Horner, 2009), should diminish if not minimize any misconducts or deviant behaviors. However, even with a monitoring and sanctioning system in place, loafing within the workplace still thrive (Carpenter, 2007). In Taiwan, teaching within a public academic institution can be translated into being tenured for life. Permanent teachers working in public elementary or high school are actually considered as public servant and/or government employees; thus, most of the faculty tends to work till they retire. More important is that as long as the teacher is working within the boundaries of what is expected of them, rarely does a faculty get terminated. In effect, faculty might become relax and let down their guard, hence, CWBs becomes a common activity (Y.-L. Hu et al., 2015).

Within the above-mentioned issues, the current study hypothesizes that perceived loafing (PL) of peers and/or co-teachers is mediated by an individual's revenge motive (RM), which in turn affects the prevalence of $C W B$ s. Furthermore, the current study also investigates the role of monitoring and sanctioning (MAS) towards an individual's tendency to loaf. As with understanding of the various inter-relationships of the different antecedents of CWBs, further policy that can help minimize or even hinders deviant behaviors from occurring can be properly implemented.

\section{Background literature}

\subsection{Counterproductive work behavior}

The notion of CWB is not new with various studies suggesting different structures and concepts (Marcus, Taylor, Hastings, Sturm, \& Weigelt, 2016). Different interpretations of the behaviors are shown in different studies, some common concepts are unethical behaviors (G. E. Jones \& Kavanagh, 1996; Reiss \& Mitra, 1998; Umphress, Bingham, \& Mitchell, 2010), deviant behaviors (Bennett \& Robinson, 2000; Peterson, 2002; Robinson \& Bennett, 1995), and even anti-social behaviors (Bodla \& Danish, 2011; Giacolone \& Greenberg, 1997). However, one specific common fact is that CWBs seems to exists in all types of workplace (Spector et al., 2006).

A distinct idea within CWB is that it may be targeted towards the organization or to a specific individual within that organization (Robinson \& Bennett, 1995). In addition, CWB can also be distinguished by the extent of its damage, such as the behavior might be minor or simple as reading newspaper during office hours or the 
Monitoring and sanctioning, perceived loafing, revenge motive, and counterproductive work behaviors

serious issues of theft and sabotage (Y.-L. Hu et al., 2015). Simply put, CWB can be considered as an intentional act that is contrary to the institution's goal (Gruys \& Sackett, 2003; Sackett, 2002). Note the word intentional, denoting that the perpetrator is aware of what he or she is doing (Martinko, Gundlach, \& Douglas, 2002).

Looking into the various factors in classifying CWBs, Robinson and Bennett (1995) mentioned four distinct classification. The four factors are production deviance - these are the minor behaviors that are still considered harmful towards the institution, such as low work quality, property deviance - these are the major offenses that are damaging to the institution, such as theft, political deviance - these are the minor behaviors towards peers and co-workers, such as blaming or finger pointing, and personal aggression - these are the major offenses towards peers and co-workers, such as abuse and harassment (Robinson \& Bennett, 1995, p. 565). Later on, Spector et al. (2006) re-classify the four factors into five groups, namely: abuse towards others, production deviance, sabotage, theft, and withdrawal. Withdrawal in the workplace is best described as exhibiting altruism, lateness to work, and absenteeism (Barling \& Phillips, 1993; Hammer, Bauer, \& Grandey, 2003; Paillé \& Grima, 2011), while the remaining four are previously discussed and self-explanatory.

In Taiwan, a recent study on the CWB model in Taiwan (CWB-T) by Hu et al. (2015) noted eight distinct factors that are present within the academic workplace. The factors are as follows: time theft (TT) - these include any form of improper or inappropriate reasons for reducing work hours, inappropriate use of resources (IUR) - these include the deliberate use, waste, theft, or destruction of schools' properties, inappropriate student-teacher relationship (ISR) - these include any inappropriate, unethical, or unprofessional interactions between teachers and students, inappropriate parent-teacher relationship (IPR) - these include any inappropriate, unethical, or unprofessional interactions between teachers and parents, lack of professionalism (LOP) - these include all the reasons resulting to poor teaching performance, might be from the lack of pedagogical and professional content knowledge in the part of the teacher, apathy (AP) - these include the lack of enthusiasm and/or altruism, and unwilling to improve oneself, political tactics (PT) - these include forming alliances to gain control of a situation and/or initiate personal attacks, and reluctant to accept administrative duties (RAD) - these include the situation wherein a teacher is unwilling to accept any administrative responsibilities besides teaching (Y.-L. Hu et al., 2015, p. 71).

In sum, the concept of CWB is both varied and multi-dimensional. More importantly, the effects of CWB are serious, no matter if it is just a simple and minor action. Within the school, students are able to observe how teachers undertake their everyday activities. Students are able to learn by just observing their teachers (Lumpkin, 2008), therefore, it is quite important that CWB be kept to a minimum within the academic workplace.

\subsection{Loafing}

The concept of loafing has been evolving. Even within a study published twenty years ago, Sunoo (1996) already noted the changing nature of loafing. To further understand loafing, some early papers are discussed. Starting with a seminal German literature, Moede (1927) noted that within a rope pulling task, adding people to the task (or increasing the group size) is not actually equivalent to sum of all the individual efforts of each of the group member. In other words, within any given task, increasing the number of people working on the task does not necessary translate to faster task completion. Adding individuals to the task might even promote social loafing (Latané, Williams, \& Harkins, 1979). This is more evident when an individual believes that his or her own personal contribution to the group effort is vague and unrecognized (Liden, Wayne, Jaworski, \& Bennett, 2004; Mulvey \& Klein, 1998; Price, Harrison, \& Gavin, 2006). In fact, as the group size increases, the chances of social loafing also increases (Breckler, Olson, \& Wiggins, 2006).

As the concept of loafing evolves, the extent of time wasted in the workplace also increases. There is already a blurring of the thin line between working and loafing, while, at the same time, new ways in wasting time are also forming. Sunoo (1996) noted the uncertainty of what can be considered as loafing. For instance, the need for 
sales agents to familiarized with all of the company's products, which is usually done through browsing the company's website. In fact, how can a manager tell if the employee is really studying or just browsing other sites? In reality, the practice of self-responsibility in part of the employee and the employer having faith or believing in their employees, as far more encouraging in the workplace (Sunoo, 1996). With the advent of the social networking era, loafing now takes the form of cyberspace as what is known as cyberloafing (Ahmadi et al., 2011; Çınar \& Karcıoğlu, 2015; Lim \& Chen, 2012; Lim \& Teo, 2005). Needless to say, the problem of loafing is increasing and exists in all types of organization (Kidwell, 2010).

As for the various causes of loafing, Price and his colleagues (2006) noted the two prominent reasons for loafing, which are dispensability and fairness. As mentioned before, dispensability happens when an employee perceived that his or her work contributions as negligible; hence, they will just the let the other employees with greater responsibility accomplished the task (Price et al., 2006). As with fairness within the workplace, much research has been made in this line of thinking. Fairness in the workplace is affected, when inequality is perceived by the employee (Ahmadi et al., 2011; Hung, Chi, \& Lu, 2009; Murphy, Wayne, Liden, \& Erdogan, 2003). More so, when the employee is a member of a certain age group, ethnicity/culture, gender, or even marital status (Tsaw, Murphy, \& Detgen, 2011); when the majority rule always take precedence, fairness in the workplace is affected. In essence, the occurrence of loafing in the workplace is greatly influenced by how management decision making take place and how each individual employee value his or her own work within the organization.

\subsection{Monitoring and sanctioning}

The notion of monitoring and sanctioning within the workplace is a fairly new concept, wherein the idea is initially discussed within organizational studies. Early studies suggest that monitoring and sanctioning to be observed between peers in order to prevent and preempt misconduct (Lazega, 2000). However, some believed that mutual monitoring can actually decrease the willingness of the group members to cooperate with each other (Orr, 2001). Monitoring and sanctioning ironically is usually compared with the Orwell's classic 1984, which cited the possibility of somebody is always watching over (Alge \& Hansen, 2014). Although the notion of Big brother seems to denote a negative atmosphere, nonetheless, monitoring seems to work better when used appropriately with just the right amount sanctioning (Zoghbi-Manrique-de-Lara, 2011).

In some studies, it is noted that monitoring also moderates the occurrence of both integrity and CWB (Fine, Horowitz, Weigler, \& Basis, 2010), which performs a sort of policing within the workplace. In other words, when there is a policeman on the corner, people behave and patiently wait for the red signal to turn green, before driving on, however, one can just take a right turn when the cop is not around. In another spectrum, within the academic setting, monitoring and sanctioning is often portrayed within students (Kelly, 2008; Sloep et al., 2007), appropriate discipline actions are actually seen as a necessity in supporting positive behaviors (Sugai \& Horner, 2008; Sugai, Sprague, Horner, \& Walker, 2000). In sum, as teachers are role models of integrity and accountability, proper monitoring and sanctioning can be seen as just normal day to day function within the school.

\subsection{Revenge motive}

As mentioned in the above literature, when inequality exists within the workplace, employees react. This inequality or sometimes also referred to as injustice is believed to be quite related to the occurrence of CWB (D. A. Jones, 2009). More important is that the resulting reaction from the presence of injustice and/or inequality within the workplace can be manifested in terms of a type of revenge (Skarlicki \& Folger, 1997). A unique perspective is that this urge for revenge is often considered as a mediator for retaliatory behavior; attitudes that can be considered as CWBs (Hung et al., 2009). However, this is contingent to the perceived level of procedural justice or in other words how monitoring and sanctioning is actually taking place (Aquino, Galperin, \& Bennett, 2004). In essence, the desire for revenge can be seen as a way to get even with the perceived inequality that is 
Monitoring and sanctioning, perceived loafing, revenge motive, and counterproductive work behaviors happening in the workplace.

\section{Design}

\subsection{Framework}

This quantitative study is designed as a cross-sectional one, wherein data is collected at one point in time (Mann, 2003). Data is collected in order to evaluate a proposed model explaining the CWB within Taiwan academic setting. Based on the previous mentioned literature, the framework of this study builds on the theory of perceived loafing (PL), monitoring and sanctioning (MAS) within the campus, revenge motive (RM) as an aggressive intention, and the concept of CWB-T. Within the model, it is assumed that PL and MAS are the latent independent variables (IV), while RM as the latent mediator, and CWB-T as the latent dependent variable (DV). Proposed hypotheses are as follows (see figure 1 for the hypothesized theoretical model of the study):

- Hypothesis 1 (H1): PL has significant positive effect on RM.

- Hypothesis 2 (H2): RM has significant positive effect on CWB-T.

- Hypothesis 3 (H3): RM mediates the relationship between PL and CWB-T.

- Hypothesis 4 (H4): MAS has significant negative effect on CWB-T.

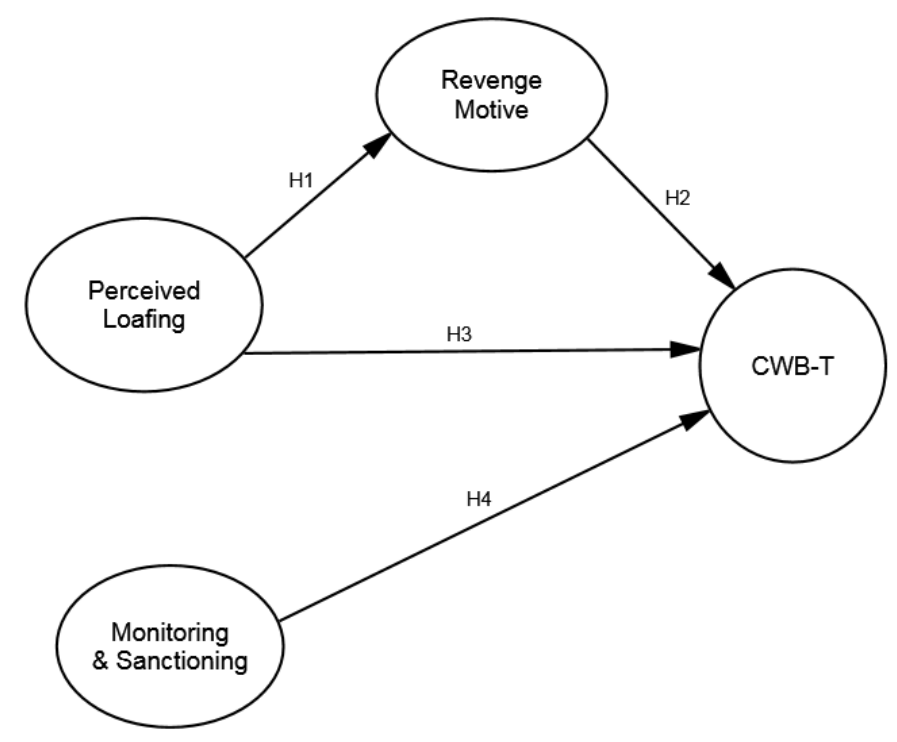

Figure 1. Hypothesized theoretical model

\subsection{Participants}

Participants of the study are 935 teachers from randomly selected primary and secondary (junior and senior high school) schools from the Northern and Central Taiwan region. Table 1 shows the various demographical backgrounds of the participants. The numbers of male and female teachers are almost equal with 467 and 468 respondents respectively. Of the participants $30 \%$ are teachers with teaching only duties, 35\% are teachers who are also class advisers (these teachers have additional responsibilities of taking care of the students during homeroom periods), $27 \%$ are teachers with administrative duties (these are teachers that have lesser teaching loads, but need to assume other responsibilities as an administrator), $6 \%$ are administrative staff, and the remaining 3\% are school principals. For the respondents' educational attainment, $45 \%$ of the teachers have a bachelor's degree, while the remaining $55 \%$ are graduate degree holders (either masters or doctoral degree). This 
Hu, Y.-L., Hung, C.-H., \& Ching, G. S.,

is actually quite impressive, wherein more than half of the participants have high educational attainment.

As for the participants' school location, $44 \%$ are from the Northern Taiwan (the capital region: Taipei and New Taipei City), while $47 \%$ are from the Central Taiwan area. For the school size, $10 \%$ are from small schools (these are schools with 12 or less than 12 classes), $44 \%$ are from medium schools (number of classes of medium schools are from 13 to 48 classes), and $46 \%$ are from large schools (these are schools with more than 48 classes). For the school district, $70 \%$ are from the urban cities, $25 \%$ are from the rural areas, and the remaining $5 \%$ are from remote locations such as the outer islands and/or mountain regions.

Table 1

Participants' demographic background $(N=935)$

\begin{tabular}{|c|c|c|c|c|c|}
\hline Demographics & $n$ & $\%$ & Demographics & $n$ & $\%$ \\
\hline Gender & & & School location & & \\
\hline Male & 467 & $50 \%$ & Northern Taiwan & 411 & $44 \%$ \\
\hline Female & 468 & $50 \%$ & Central Taiwan & 437 & $47 \%$ \\
\hline Position & & & School size & & \\
\hline Subject teacher & 276 & $30 \%$ & Small (12 class and below) & 94 & $10 \%$ \\
\hline Teacher w/ class adviser duties & 324 & $35 \%$ & Medium (13 to 48 class) & 413 & $44 \%$ \\
\hline Teacher $\mathrm{w} /$ administrative duties & 251 & $27 \%$ & Large (49 class and above) & 428 & $46 \%$ \\
\hline Administrative staff & 53 & $6 \%$ & District & & \\
\hline School Principal & 31 & $3 \%$ & Urban (city) & 652 & $70 \%$ \\
\hline Educational attainment & & & Rural & 234 & $25 \%$ \\
\hline Bachelor degree & 424 & $45 \%$ & Remote (outer islands and/or & 49 & $5 \%$ \\
\hline Graduate program & 511 & $55 \%$ & mountain region) & & \\
\hline
\end{tabular}

\subsection{Procedures}

A call to participate in the study was disseminated to strategically selected schools located at the Northern and Central Taiwan region. Schools were selected to reflect the actual ratio based on the school size gathered from the 2015 Ministry of Education database. After the school selection process, an invitation for volunteer participation was sent. To comply with the requirements of the research protocol, participants are informed that they are allowed to skip any question or withdraw from survey any time they wish. After one month of data collection, a total of 935 valid responds are collected. Data analysis included the recoding of the CWB-T scores, social desirability check, reliability check, and model fit analysis using the structured equation modelling (SEM).

\subsection{Measures}

Counterproductive Work Behaviors Taiwan (CWB-T) - The CWB-T is recent scale developed by Hu and her associates (2015) specifically designed for collecting the perceived CWB occurrence within an academic setting. Within their study, a total of eight factors are determined. The factors are as follows: time theft (TT) these include any form of improper or inappropriate reasons for reducing work hours, inappropriate use of resources (IUR) - these include the deliberate use, waste, theft, or destruction of schools' properties, inappropriate student-teacher relationship (ISR) - these include any inappropriate, unethical, or unprofessional interactions between teachers and students, inappropriate parent-teacher relationship (IPR) - these include any inappropriate, unethical, or unprofessional interactions between teachers and parents, lack of professionalism (LOP) - these include all the reasons resulting to poor teaching performance, might be from the lack of pedagogical and professional content knowledge in the part of the teacher, apathy (AP) - these include the lack of enthusiasm and/or altruism, and unwilling to improve oneself, political tactics (PT) - these include forming alliances to gain control of a situation and/or initiate personal attacks, and reluctant to accept administrative duties (RAD) - these include the situation wherein a teacher is unwilling to accept any administrative responsibilities besides teaching (Y.-L. Hu et al., 2015, p. 71). The composite reliabilities (CR) of the original factors range from .83 to .92 . 
Monitoring and sanctioning, perceived loafing, revenge motive, and counterproductive work behaviors

Items are initially collected with a 4-point Likert (1932) type scale ranging from 0 to 3; denoting never to always. These are recoded based on $\mathrm{Hu}$ et al. (2015) suggestions to either $\boldsymbol{O}$ for none occurrence and $\boldsymbol{l}$ for possible occurrence. Hence, items are now dichotomous ranging from none to possible occurrence. After recoding, Cronbach (1951) alpha values of the factors are computed again with resulting to increased reliabilities. Lastly, in order to lower the complexity of the computation, the eight factors are used into the model as manifest variables.

Perceived loafing (PL) - To collect the perceived loafing of coworkers, the current study used the scale developed by Mulvey and Klein (1998) exhibiting a four item scale, for instance: Teachers in my school are trying as hard as they can do (reverse coded) and Teachers in my school are contributing less than I anticipated. Responses are collected based on a 4-point Likert (1932) type scale denoting 1 as strongly disagree to 4 strongly agree. Lastly, Cronbach (1951) alpha reliability of the original scale is computed at .74, denoting a reliable scale.

Revenge Motive (RM) - To collect the tendency for revenge, the current study used the scales developed by Jones (2009), wherein there are two factors with two duplicating items each referring to either organization or coworkers, namely: Revenge motive towards the organization (RMTO) and revenge motive towards coworkers (RMTC). Sample items are as such: If I were mistreated by the school, the satisfaction of "getting even" would outweigh the risks of getting caught (RMTO) and If I were mistreated by my coworkers, it would feel good to "get back" in some way (RMTC). Responses are also collected based on a 4-point Likert (1932) type scale denoting 1 as strongly disagree to 4 strongly agree. Cronbach (1951) alpha reliabilities of the original scales are computed at .87 and .82 , denoting a quite reliable scale. Lastly, according to the study made by Hung et al. (2009) and Jones (2009), both RMTO and RMTC should be regarded as two latent variables separately in order to predict CWB-Organization and CWB-Individual. However, in our model, CWB-T is considered as a higher order factor; hence, both CWBs towards organization and individual are already included. Therefore, within the current study, RMTO and RMTC are combined to form one single construct called revenge motive (RM).

Monitoring and sanctioning (MAS) - For the current study, monitoring and sanctioning is collected with the use of the security control norm scale developed by Fine et al. (2010) to measure the perceived monitoring and consequences of CWBs. Within their scale, eight items were used to collect the perceived monitoring and sanction dimension of security control norm. Some items are Employees' understandings of what happens if they deviate from company policy and instruction, This workplace tends to deal strictly with employees who deviate from policies and instructions, and This place of work actively monitors and inspects its employees. However, it is noted that the security control norm scale is highly related to an individual's integrity (Furnham \& Taylor, 2011), hence, within the academic setting, it would be in the teachers' nature to be aware of the monitoring and sanctioning that is occurring within the academic workplace. Original Cronbach (1951) alpha reliabilities of the scale is computed at .80 with data collected using a 4-point Likert (1932) type scale denoting 1 as strongly disagree to 4 strongly agree. Lastly, in order to lower the complexity of computation, the researchers used the mean score of the eight items and place the resulting mean into the model as a single indicator.

\subsection{Reliability and validity}

It is always important that within a self-reported survey; especially within sensitive issues such as CWB, that the case of social desirability is handled carefully (Fisher \& Katz, 2000; Kreuter, Presser, \& Tourangeau, 2008; van de Mortel, 2008). To handle this situation, the current study followed the recoding scheme of Hu et al. (2015), wherein the initial Likert (1932) type scale ranging from 0 to 3 for the CWB-T; denoting the perceived occurrence of CWBs from never to always, was recoded into either 0 for none occurrence and 1 for possible occurrence of CWBs. After the recoding of the CWB-T items, all of the Cronbach (1951) alpha reliabilities increased slightly. Therefore, making the scale more reliable (Cohen, Manion, \& Morrison, 2007).

As for the effects of social desirability, the current study also administered the 10 item short-form of Marlowe-Crowne Social Desirability Scale (SDS) (Fisher \& Katz, 2000) together with the other scale and 
Hu, Y.-L., Hung, C.-H., \& Ching, G. S.,

compared the correlation of the results with the different CWB-T factors. Table 2 shows the various mean scores of the SDS scale. As for the correctional analyses, results show that only three CWB-T factors are slightly correlated with SDS. Such as IUR with $r=.067, p=.041, n=935$, ISR with $r=.085, p=.010, n=935$, and LOP with $r=.076, p=.020, n=935$. In sum, most of the CWB-T factors are still unaffected by SDS, hence, results of the scale can be considered as an actual reflection of the CWB situations within the academic workplace.

Table 2

Mean scores of social desirability scale $(N=935)$

\begin{tabular}{llcc}
\hline \multicolumn{1}{c}{ Code } & \multicolumn{1}{c}{ Factor/Items/Cronbach Alpha reliability } & $M$ & $S D$ \\
\hline SDS & $\quad$ Social Desirability Scale $(\alpha=.76)$ & 2.48 & 0.40 \\
SD01* & There have been times when I was quite jealous of the good fortune of others & 2.08 & 0.70 \\
SD02* & I sometimes feel resentful when I don't get my own way & 2.16 & 0.70 \\
SD03* & On a few occasions, I have given up doing something because I thought too & 2.21 & 0.85 \\
& little of my ability & 1.91 & 0.75 \\
SD04* & There have been occasions when I took advantage of someone & 1.91 & 0.80 \\
SD05* & I can remember "playing sick" to get out of something & 2.61 & 0.72 \\
SD06 & I have never been irked when people expressed ideas very different from my & & \\
& own & 2.85 & 0.68 \\
SD07 & I am always courteous, even to people who are disagreeable & 2.97 & 0.68 \\
SD08 & No matter who I'm talking to, I'm always a good listener & 3.04 & 0.59 \\
SD09 & I'm always willing to admit it when I make a mistake & 3.07 & 0.59 \\
SD10 & When I don't know something I don't mind at all admitting it & &
\end{tabular}

Note. Data collected using 4-point Likert scale. *Reverse coded items.

\subsection{Descriptive statistics}

For the data analysis, the current study used the Statistical Package for the Social Sciences (SPSS) version 20 software to accomplished the various computation, while the model verification is accomplished using the statistical method of structure equation modelling (SEM) with the help of the program Amos version 20 software. Table 3 shows the various mean scores of the CWB-T items and factors, together with the various Cronbach (1951) alpha reliabilities. Note that the reliabilities of the CWB-T factors ranges from .70 to .89 reflecting a reliable instrument (Cohen et al., 2007).

Looking at the mean scores, Table 3 shows that $\boldsymbol{T T}$ has the highest perceived occurrence with an overall mean score of 0.66; denoting that around 66\% likely occurrence of stealing time and doing inappropriate tasks. Actually these are in fact considered as loafing (Brock, Martin, \& Buckley, 2013; Snider, 2001). Highest item within TT are Doing personal stuff while on duty with a mean of 0.86, Being online (personal internet surfing; FB) while on duty with a mean of 0.75 , Chatting while on duty with a mean of 0.73 , Leaving without asking for leave with a mean of 0.71, and Coming to school late and/or going home early with a mean of 0.70. The occurrence of these CWBs is actually quite high, as their mean scores are higher than $70 \%$ indicating a high chance of happening within the academic workplace.

Table 3

Mean scores of CWB-T items ( $N=935)$

\begin{tabular}{|c|c|c|c|}
\hline Code & Factors/Items/Cronbach Alpha reliability & $M$ & $S D$ \\
\hline$\overline{\mathrm{TT}}$ & Time Theft $(\alpha=.81)$ & 0.66 & 0.31 \\
\hline TT01 & Lying about being sick & 0.45 & 0.50 \\
\hline TT02 & Leaving without asking for leave & 0.71 & 0.45 \\
\hline TT03 & Coming to school late and/or going home early & 0.70 & 0.46 \\
\hline TT04 & Asking for leave regardless of the work situation & 0.39 & 0.49 \\
\hline TT05 & Doing personal stuff while on duty & 0.86 & 0.35 \\
\hline TT06 & Being online (personal internet surfing; FB) while on duty & 0.75 & 0.43 \\
\hline TT07 & Chatting while on duty & 0.73 & 0.44 \\
\hline
\end{tabular}


Monitoring and sanctioning, perceived loafing, revenge motive, and counterproductive work behaviors

Table 3 ... continued

\begin{tabular}{|c|c|c|c|}
\hline Code & Factors/Items/Cronbach Alpha reliability & $M$ & $S D$ \\
\hline IUR & Inappropriate Use of Resources $(\alpha=.70)$ & 0.29 & 0.30 \\
\hline IUR01 & Waste of school's resources & 0.52 & 0.50 \\
\hline IUR02 & Occupying school's resources as if one's own property & 0.44 & 0.50 \\
\hline IUR03 & Stealing school resources & 0.11 & 0.31 \\
\hline IUR04 & Destruction of school's resources & 0.09 & 0.29 \\
\hline ISR & Inappropriate Student-teacher Relationship $(\alpha=.85)$ & 0.50 & 0.34 \\
\hline ISR01 & Favoritism or discriminating specific students & 0.72 & 0.45 \\
\hline ISR02 & Improper student punishment & 0.63 & 0.48 \\
\hline ISR03 & Mocking students & 0.51 & 0.50 \\
\hline ISR04 & Discrimination against students & 0.22 & 0.41 \\
\hline ISR05 & Deliberate singling out of specific students & 0.33 & 0.47 \\
\hline ISR06 & Focusing only on students with good grades and ignoring others & 0.49 & 0.50 \\
\hline ISR07 & Separated and cold towards students' problems & 0.57 & 0.50 \\
\hline$\overline{\mathrm{IPR}}$ & Inappropriate Parent-teacher Relationship $(\alpha=.81)$ & 0.28 & 0.34 \\
\hline IPR01 & Deliberate concealment or providing misleading information & 0.36 & 0.48 \\
\hline IPR02 & Improper behavior in front of parents & 0.37 & 0.48 \\
\hline IPR03 & Encouraging parents to go against the school & 0.24 & 0.43 \\
\hline IPR04 & Conniving with parents & 0.14 & 0.34 \\
\hline IPR05 & Ignoring or unwilling to communicate with parents & 0.32 & 0.46 \\
\hline LOP & Lack of Professionalism $(\alpha=.85)$ & 0.55 & 0.37 \\
\hline LOP01 & Inadequate teacher preparation & 0.57 & 0.50 \\
\hline LOP02 & Not following proper curriculum & 0.55 & 0.50 \\
\hline LOP03 & Saying improper things during class & 0.50 & 0.50 \\
\hline LOP04 & Too few or too much assignments/class activities & 0.70 & 0.46 \\
\hline LOP05 & Casual checking of students' assignments & 0.43 & 0.49 \\
\hline LOP06 & Improper use of teaching pedagogy (such as too much movie time) & 0.54 & 0.50 \\
\hline AP & Apathy $(\alpha=.82)$ & 0.59 & 0.35 \\
\hline AP01 & Unwilling to undergo tutoring & 0.40 & 0.49 \\
\hline AP02 & Lacks teaching enthusiasm & 0.73 & 0.44 \\
\hline $\mathrm{AP} 03$ & Wrong use of educational resources & 0.75 & 0.44 \\
\hline AP04 & Lacks professional content knowledge & 0.48 & 0.50 \\
\hline AP05 & Unwilling to participate in professional development workshops & 0.60 & 0.49 \\
\hline AP06 & Lacks the motivation to join professional development programs & 0.61 & 0.49 \\
\hline PT & Political Tactics $(\alpha=.89)$ & 0.46 & 0.38 \\
\hline PT01 & Gossiping & 0.72 & 0.45 \\
\hline РT02 & Spreading wrong/bad information & 0.43 & 0.49 \\
\hline PT03 & Improver verbal conduct & 0.36 & 0.48 \\
\hline PT04 & Deliberate neglect or ignoring others & 0.52 & 0.50 \\
\hline PT05 & Deliberate singling out others & 0.42 & 0.49 \\
\hline PT06 & Forming small groups/alliances to go against others & 0.45 & 0.50 \\
\hline PT07 & Convincing others to go against the school & 0.35 & 0.48 \\
\hline RAD & Reluctant to accept Administrative Duties $(\alpha=.79)$ & 0.61 & 0.37 \\
\hline RAD01 & Unwilling to cooperate with school administration & 0.51 & 0.50 \\
\hline RAD02 & Going against all educational reforms & 0.49 & 0.50 \\
\hline RAD03 & Unwilling to undertake administrative responsibilities & 0.75 & 0.43 \\
\hline RAD04 & Miscommunication between teachers and administrators & 0.69 & 0.46 \\
\hline
\end{tabular}

Note. Mean scores recoded into either 0 - no occurrence, 1 - possible occurrence.

Following TT, the second highest CWB-T factor is $\boldsymbol{R} \boldsymbol{A D}$ with an overall mean score of 0.61 . Note that the item Unwilling to undertake administrative responsibilities with a mean score of 0.75 denotes that around $75 \%$ of the time, faculty has refrained from accepting other duties except teaching. In addition, the CWB-T factor $\boldsymbol{A P}$ also has an overall mean of 0.59 , which is still quite high. It is sad that around $73 \%$ of the time, respondents perceived that teachers Lacks teaching enthusiasm with a mean of 0.73 . Furthermore, teachers also commit Wrong use of educational resources with a mean of 0.75. Lastly, within the LOP factor, the item Too few or too much assignments/class activities with a mean of 0.70 is also quite high. These results are actually in-line with the recent finding of Ching, Tsay, Hu, and Hung (2016), wherein $\boldsymbol{T} \boldsymbol{T}$ and $\boldsymbol{R} \boldsymbol{A} \boldsymbol{D}$ are the highest CWB-T factors 
Hu, Y.-L., Hung, C.-H., \& Ching, G. S.,

within the academic setting. In sum, these CWBs are seen as occurring within a moderate to high level. It is hoped that the succeeding sections should be able to shed some light with regards to the impact of perceived loafing, and monitoring and sanctioning towards an individual's revenge motive and counterproductive work behaviors.

Table 4 shows the various overall mean scores of the other factors and items used. Note that this part of the study is only distributed to 575 respondents, while the table below only depicts two items from each of the factors used in the scale. In addition, the data is collected with the use of a 4-point Likert (1932) type scale denoting 1 as strongly disagree to 4 strongly agree. Cronbach (1951) alpha reliabilities are computed from .68 to .77 , hence, scale can be considered as reliable. As for the correlational analyses of the factors, Table 5 shows the various results with all the factors except $\boldsymbol{M A S}$ are quite correlated with each other.

\section{Table 4}

Mean scores of perceived loafing, revenge motive, and monitoring and sanctioning $(n=575)$

\begin{tabular}{|c|c|c|c|}
\hline Code & Factors/Items/Cronbach Alpha reliability & $M$ & $S D$ \\
\hline$\overline{\mathrm{PL}}$ & Perceived loafing $(\alpha=.71)$ & 1.98 & 0.42 \\
\hline PL01* & Teachers in my school are trying as hard as they can do & 1.93 & 0.48 \\
\hline PL02 & Teachers in my school are "free-loaders" & 1.77 & 0.57 \\
\hline PL03 & Teachers in my school are contributing less than I anticipated & 2.09 & 0.61 \\
\hline PL04* & Given their abilities, teachers in my school are doing the best they can & 2.12 & 0.64 \\
\hline RMTO & Revenge motive towards organization $(\alpha=.69)$ & 2.23 & 0.51 \\
\hline RMTO1 & $\begin{array}{l}\text { If I were mistreated by the school, the satisfaction of "getting even" would } \\
\text { outweigh the risks of getting caught }\end{array}$ & 2.13 & 0.54 \\
\hline RMTO2 & If I were mistreated by the school, it would feel good to "get back" in some way & 2.33 & 0.63 \\
\hline RMTC & Revenge motive towards co-worker $(\alpha=.77)$ & 2.25 & 0.54 \\
\hline RMTC1 & $\begin{array}{l}\text { If I were mistreated by my coworkers, the satisfaction of "getting even" would } \\
\text { outweigh the risks of getting caught }\end{array}$ & 2.14 & 0.57 \\
\hline RMTC2 & $\begin{array}{l}\text { If I were mistreated by my coworkers, it would feel good to "get back" in some } \\
\text { way }\end{array}$ & 2.35 & 0.63 \\
\hline MAS & Monitoring and sanctioning $(\alpha=.68)$ & 2.22 & 0.50 \\
\hline MAS1 & $\begin{array}{l}\text { This workplace tends to deal strictly with employees who deviate from policies } \\
\text { and instructions }\end{array}$ & 2.02 & 0.64 \\
\hline MAS2 & This place of work actively monitors and inspects its employees & 2.42 & 0.63 \\
\hline
\end{tabular}

\section{Table 5}

Correlational analysis of the various factors $(N=935)$

\begin{tabular}{|c|c|c|c|c|c|c|c|c|c|c|c|c|}
\hline Factors & TT & IUR & ISR & IPR & LOP & AP & $\mathrm{PT}$ & RAD & $\mathrm{PL}$ & RMTO & RMTC & MAS \\
\hline TT & 1 & & & & & & & & & & & \\
\hline IUR & $.627 * *$ & 1 & & & & & & & & & & \\
\hline ISR & $.592 * *$ & $.647 * *$ & 1 & & & & & & & & & \\
\hline IPR & $.516^{* *}$ & $.635 * *$ & $.688 * *$ & 1 & & & & & & & & \\
\hline LOP & $.578 * *$ & $.615^{* *}$ & $.722 * *$ & $.674 * *$ & 1 & & & & & & & \\
\hline AP & $.545 * *$ & $.563 * *$ & $.663 * *$ & $.625 * *$ & $.750 * *$ & 1 & & & & & & \\
\hline PT & $.520 * *$ & $.534 * *$ & $.638 * *$ & $.660 * *$ & $.642 * *$ & $.659 * *$ & 1 & & & & & \\
\hline RAD & $.504 * *$ & $.495 * *$ & $.561 * *$ & $.579 * *$ & $.630 * *$ & $.690 * *$ & $.698 * *$ & 1 & & & & \\
\hline PL & $.193 * *$ & $.234 * *$ & $.200 * *$ & $.266 * *$ & $.197 * *$ & $.240 * *$ & $.259 * *$ & $.258 * *$ & 1 & & & \\
\hline RMTO & $.285^{* *}$ & $.243 * *$ & $.274 * *$ & $.309 * *$ & $.231 * *$ & $.278 * *$ & $.321 * *$ & $.246^{* *}$ & $.315^{* *}$ & 1 & & \\
\hline RMTC & $.295 * *$ & $.246 * *$ & $.287 * *$ & $.355 * *$ & $.279 * *$ & $.328 * *$ & $.348 * *$ & $.305^{* *}$ & $.372 * *$ & $.780 * *$ & 1 & \\
\hline MAS & -.069 & $-.084 *$ & -.054 & -.014 & -.011 & -.034 & .014 & .022 & $.210 * *$ & $.235 * *$ & $.276 * *$ & 1 \\
\hline
\end{tabular}




\section{Model verification}

\subsection{Preliminary analyses}

For the preliminary analysis, CR and average variance extracted (AVE) of the proposed model was used to prove the reliability and validity of measurement model, while the structure model was used to explain the relationship and effect among latent variables. SEM was estimated using the maximum-likelihood method in the AMOS 20 program (Arbuckle, 2011). With the different (uneven/unequal) number of items for each of the factor, for simplicity, the overall mean scores of each of the factors are used to represent the different variables. Multivariate normality test was used to examine whether the data met the normality assumptions underlying the maximum-likelihood procedure used to test the models in the present study. The results of the multivariate normality test indicated that the data were multivariate normal, multivariate kurtosis was 12.30. Hence, maximum-likelihood method was considered appropriate (see Tables 3 and 4 for the various overall mean scores and standard deviations).

\subsection{Measurement model}

Before a structural model is tested, Anderson and Gerbing (1988) suggested conducting a confirmatory factor analysis to examine whether the measurement model provides an acceptable fit to the data. Once an acceptable measurement model is developed, the structural model can be tested. Furthermore, following (Tucker and Lewis (1973), Byrne (2009), and Hu and Bentler (1999) suggestions, six fit indices were used to assess goodness of fit for the models. The indices are as such: the goodness of fit index (GFI; values $>0.90$ indicate good fit), the comparative fit index (CFI; values $>0.90$ indicate good fit), the Tucker-Lewis index (TLI; values $>0.90$ indicate good fit), the non-normed fit index (NFI; values $>0.90$ indicate good fit), the root-mean-square error of approximation (RMSEA; values $<0.08$ indicate good fit), and the standardized root mean square residual (SRMR; values $<0.08$ indicate good fit).

A test of the measurement model resulted in a relatively good fit to the data $\left(\chi^{2}=184.90^{* * *}, d f=72\right.$, GFI $=.93, \mathrm{CFI}=.96, \mathrm{TLI}=.95, \mathrm{NFI}=.94, \mathrm{RMSEA}=.066, \mathrm{SRMR}=.035)$. All of the standardized loadings of the measured variables on the latent variables were statistically significant with $p<.001$ (see Table 6). CR of the latent variables ranging from .73 .93, AVE ranging from .48 .79, while both CR and AVE are fit to the standards suggested by Fornell and Larcker (1981) and Hair, Black, Babin, and Anderson (2010). Therefore, all of the latent variables appear to have been adequately operationalized by their respective indicators. In addition, most of correlations among the independent latent variables, the mediator latent variable, and dependent latent variables were statistically significant with $p<.001$ (see Table 7 for the correlational analysis and Table 8 for the factor loadings, CR, and AVE of the measurement model).

\section{Table 6}

Model fit indices

\begin{tabular}{cccc}
\hline Indices & Measurement model & Structural model & Criteria \\
\hline$n$ & 309 & 626 & \\
$\chi^{2}$ & $184.90^{* * *}$ & 356.74 & \\
$d f$ & 72 & 73 & $>.90$ \\
GFI & .93 & .93 & $>.90$ \\
CFI & .96 & .95 & $>.90$ \\
TLI & .95 & .94 & $>.90$ \\
NFI & .94 & .93 & $<.08$ \\
RMSEA & .066 & .068 & $<.05$ \\
SRMR & .035 & .040 &
\end{tabular}


Hu, Y.-L., Hung, C.-H., \& Ching, G. S.,

Table 7

Correlations matrix for the Measurement Model (33\% sample, $n=309$ )

\begin{tabular}{lllll}
\hline \multicolumn{1}{c}{ Latent variables } & $(1)$ & $(2)$ & $(3)$ & $(4)$ \\
\hline (1) CWB-T & 1 & & & \\
(2) Revenge motive & $.42^{* * *}$ & 1 & & \\
(3) Perceived loafing & $.35^{* * *}$ & $.46^{* * *}$ & 1 & \\
(4) Monitoring and sanctioning & -.02 & $.29^{* * *}$ & $.31^{* * *}$ & 1 \\
\hline Note $* * * p<001 \quad$ Shaded values $=$ no significant correlation & &
\end{tabular}

Note. ${ }^{* * *} p<.001$. Shaded values $=$ no significant correlation.

\section{Table 8}

Factor loadings for the Measurement Model (33\% of sample, $n=309)$

\begin{tabular}{|c|c|c|c|c|c|}
\hline Factors/Items & Standardized factor loading & $S E$ & $t$ & AVE & $\mathrm{CR}$ \\
\hline CWB-T & & & & .63 & .93 \\
\hline TT & .68 & & & & \\
\hline IUR & .73 & 0.08 & 12.72 & & \\
\hline ISR & .83 & 0.09 & 14.30 & & \\
\hline IPR & .82 & 0.09 & 14.05 & & \\
\hline LOP & .85 & 0.10 & 14.53 & & \\
\hline AP & .84 & 0.09 & 14.40 & & \\
\hline PT & .80 & 0.10 & 13.87 & & \\
\hline RAD & .77 & 0.10 & 13.38 & & \\
\hline Revenge motive & & & & .79 & .88 \\
\hline RMTO & .85 & & & & \\
\hline RMTC & .93 & 0.08 & 14.06 & & \\
\hline Perceived loafing & & & & .48 & .73 \\
\hline PL01 & .63 & & & & \\
\hline PL02 & .78 & 0.16 & 9.43 & & \\
\hline PL03 & .66 & 0.15 & 9.08 & & \\
\hline Monitoring and sanctioning & & & & & \\
\hline MAS & 1.00 & & & & \\
\hline
\end{tabular}

\subsection{Structural model for testing the mediated effects}

For the testing of the mediated effects of the structural model, SEM was also used. Within the computation for the mediated effects, PL and MAS were taken as latent IV, RM as latent mediator, and CWB-T as latent DV. Results of SEM analysis shows a good fit of the model to the data with $\chi^{2}=356.74^{* * *}, d f=73$, GFI $=.93$, CFI $=.95, \mathrm{TLI}=.94, \mathrm{NFI}=.93, \mathrm{RMSEA}=.068, \mathrm{SRMR}=.040$ (see Figure 2). In addition, path effect (or sometimes referred to as direct effect) are computed to be significant with $p<.001$, while exhibiting a medium effect size.

Furthermore, MacKinnon, Lockwood, Hoffman, West, and Sheets (2002) noted the many approaches in examining mediation with consideration for Type I error and statistical power. They mentioned that although most studies used the strategy as proposed by Baron and Kenny (1986); which has the least power, many also relied on the application of the Sobel (1982) in examining the significance of mediation effect. However, there is evidence that the distribution of the mediation effect is not normal (Bollen \& Stine, 1990; MacKinnon \& Dwyer, 1993; Stone \& Sobel, 1990), while the utilization of the significance tests such as the Sobel test, which assumes a normal distribution when examining the mediation effect, is actually not appropriate. Therefore, in order to remedy this, Shrout and Bolger (2002) suggested the use of the bootstrap method, which they proposed should be a better way of examining mediation.

Within Shrout and Bolger (2002) suggestion, the bootstrap method acquires 95\% confidence intervals (CI) for the indirect effect by resampling procedure. Based on the central limit theorem, bootstrap method is still considered to be robust even if the distribution of mediation effect is not normal. If $95 \% \mathrm{CI}$ for the estimates of 
Monitoring and sanctioning, perceived loafing, revenge motive, and counterproductive work behaviors

the indirect effects based on 5000 indirect effect estimates does not include zero, then it can be concluded that the indirect effect is statistically significant at the .05 level. Therefore, after the structural models were examined through the AMOS 20 program, the bootstrap procedure was used to test whether or not the indirect effects were statistically significant.

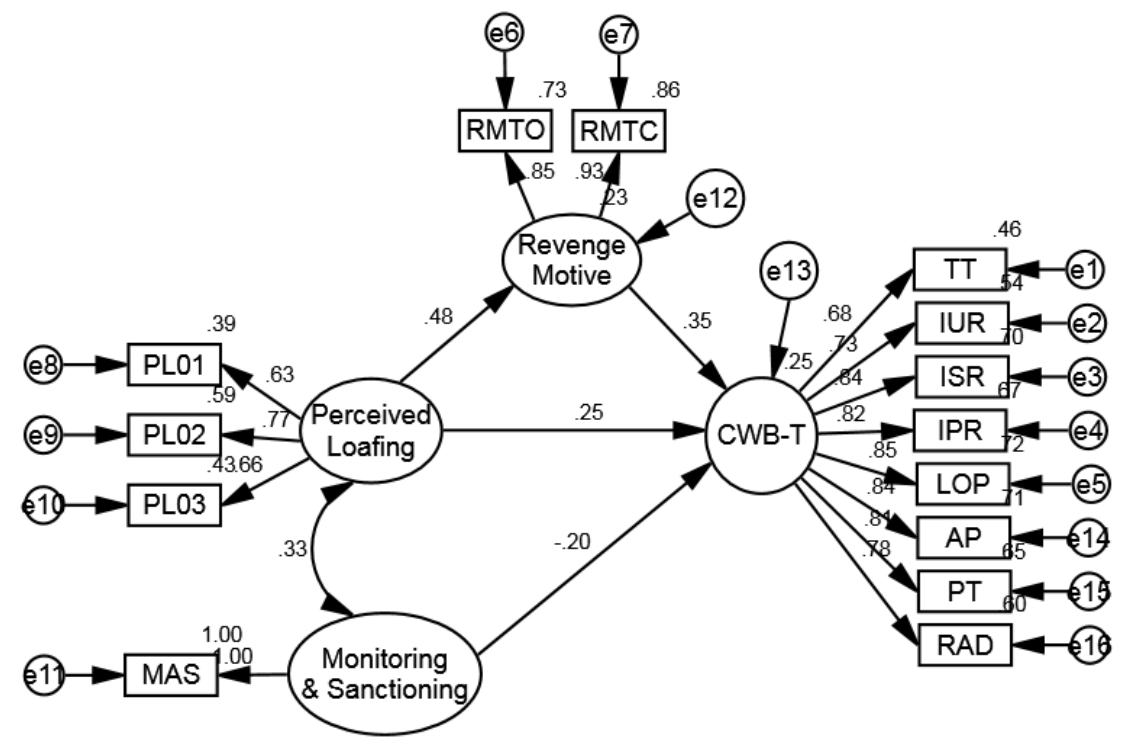

Figure 2. Structure equation model with maximum likelihood estimates (standardized)

It is computed that the indirect effect (or mediation effect) from $\boldsymbol{P L}$ to $\boldsymbol{C W B}-\boldsymbol{T}$ is -.17 . The $95 \%$ CI for the estimates of the indirect effects ranges from .11 .24 and does not include zero, therefore, it can be concluded that the mediation effect is statistically significant at the .05 level (see Table 9). In practical terms, results show that within the Taiwan school campus, $\boldsymbol{R} \boldsymbol{M}$ plays the role of mediator between $\boldsymbol{P L}$ and $\boldsymbol{C W B}-\boldsymbol{T}$. In addition, the total effect is computed using the summation of the direct and indirect effect, hence, the total effect from PL to $\boldsymbol{C W B}-\boldsymbol{T}$ is .42, with $95 \% \mathrm{CI}$ for total effects ranging from .29 .52 and does not include zero. Therefore, the total effect is also statistically significant at the .05 level. Lastly, the total effect from $\boldsymbol{M A S}$ to $\boldsymbol{C W B}-\boldsymbol{T}$ is computed to be -.20 with the $95 \%$ CI for total effects ranging from -.30 - .10 and does not include zero, hence, the total effect is statistically significant at the .05 level. This result suggests a good explained variance on $\boldsymbol{C W B}-\boldsymbol{T}$ in both positive and negative path (see Figure 2 and Table 9 for more details).

Table 9

Bootstrap analysis of Structural Model (67\% of sample, $n=626)$

\begin{tabular}{llcc}
\hline & \multicolumn{1}{c}{ Path } & Standardized Coefficient & $95 \%$ CI \\
\hline H1 & Perceived loafing $\rightarrow$ Revenge motive & $.48^{* * * *}$ & $.35^{* * *}$ \\
H2 & Revenge motive $\rightarrow$ CWB-T & .17 & $.11 \sim .24$ \\
H3 & Perceived loafing $\rightarrow$ Revenge motive $\rightarrow$ CWB-T & $-.20^{* * *}$ & .42 \\
H4 & Monitoring and sanctioning $\rightarrow$ CWB-T & -.20 & $.29 \sim .52$ \\
& Total effect on CWB-T by Perceived loafing & & $-.30 \sim-.10$ \\
& Total effect on CWB-T by Monitoring and sanctioning &
\end{tabular}

\section{Conclusion}

Achieving equality within the workplace is important. Inside the school, students are able to learn not only during class time, but also by just observing how their teachers interact. Therefore it is quite important that teachers are always providing a good role model for the students to follow. In other words, teachers should always be aware of their behaviors and attitudes. Within the studies of organizational workplace, many revealed 
that there always exists a certain amount of CWB. This also holds true within academic institutions, wherein recent studies have shown that there are moderate occurrences of some types of these deviant behaviors. In Taiwan, previous CWB studies within the academic setting have shown that stealing time (or killing time) as the highest rated deviant activity, which the current study also confirmed. Furthermore, the occurrence of these CWB seemed to have increased as compared to previous findings.

As for the underlying relationship between PL, RM, MAS, and CWB-T, the current study proposed a structural model depicting a theory in explaining the occurrence of these deviant behaviors within the Taiwan school campus. Using the statistical method of SEM, results suggest that PL has an increasing effect on both RM and CWB-T. In addition, RM seems to act as a mediator between PL and CWB-T, while MAS exhibits a decreasing effect on PL. Therefore, the proposed hypotheses (1 to 4) are all supported. The test of mediation also confirmed the mediator role of RM between PL and CWB-T. In sum, one path from PL and RM will tend to increase the CWB-T, while the other path from MAS can decrease CWB-T.

These findings actually suggest that even within the school setting, monitoring and sanctioning of faculty should be practiced religiously. Although that policies preventing and/or preempting the occurrence of CWBs might actually be in placed even long before, many still are not aware of their existence. More importantly, since most full-time teachers within national (or public) institutions are tenured, they do not have the fear of being laid off. In some sense, nobody wants to be the whistle blower, and break the status-quo. It is hoped that the current study can become an eye opener for policy changes that would help decrease the levels of CWBs within the academic setting. Lastly, in terms of the methodology, Baron and Kenny (1986) noted that if the path of the direct effect is still significant, the mediation of the model can only be considered as only having partial mediation, therefore, there might still be other effective mediator that can be taken into consideration in future studies with regards to CWB within the academic setting.

Acknowledgement: This work is supported in part by the Taiwan Ministry of Science and Technology projects 103-2410-H-004-143 and 104-2410-H-004-151-SS2. A preliminary version of this paper was presented in the 2016 Asian Conference on Psychology and the Behavioral Sciences held in Kobe, Japan on March 31 to April 3. While, part of this paper is also accepted in the 2017 Global Educators' Conference to be held in Manila, Philippines from 27 to 29 January 2017 and shall be included in the Conference Book of Proceedings.

\section{References}

Ahmadi, H., Bagheri, F., Ebrahimi, S. A., Rokni, M. A. N., \& Safari-Kahreh, M. (2011). Deviant work behavior: Explaining relationship between organizational justice and cyber-loafing as a deviant work behavior. American Journal of Scientific Research, 24(103-116).

Alge, B. J., \& Hansen, S. D. (2014). Workplace monitoring and surveillance research since "1984": A review and agenda. In M. D. Coovert \& L. F. Thompson (Eds.), The psychology of workplace technology (pp. 209-237). New York, NY: Routledge.

Anderson, J. C., \& Gerbing, D. W. (1988). Structural equation modeling in practice: A review and recommended two-step approach. Psychological Bulletin, 103(3), 411-423. http://dx.doi.org/10.1037/0033-2909.103.3.411

Aquino, K., Galperin, B. L., \& Bennett, R. J. (2004). Social status and aggressiveness as moderators of the relationship between interactional justice and workplace deviance. Journal of Applied Social Psychology, 34(5), 1001-1029. http://dx.doi.org/10.1111/j.1559-1816.2004.tb02581.x

Arbuckle, J. L. (2011). IBM SPSS Amos 20 user's guide. Armonk, NY: IBM.

Barling, J., \& Phillips, M. (1993). Interactional, formal, and distributive justice in the workplace: An exploratory study. The Journal of Psychology, 127(6), 649-656. http://dx.doi.org/10.1080/00223980.1993.9914904

Baron, R. M., \& Kenny, D. A. (1986). The moderator-mediator variable distinction in social psychological research: Conceptual, strategic, and statistical considerations. Journal of Personality and Social Psychology, 51(6), 1173-1182. http://dx.doi.org/10.1037/0022-3514.51.6.1173

Bennett, R. J., \& Robinson, S. L. (2000). Development of a measure of workplace deviance. Journal of Applied Psychology, 85(3), 349-360. 
Monitoring and sanctioning, perceived loafing, revenge motive, and counterproductive work behaviors

Bodla, M. A., \& Danish, R. Q. (2011). Moderating role of social exchange perceptions between perceived organizational politics and antisocial behavior. Journal of Economics and Behavioral Studies, 3(5), 279-286.

Bollen, K. A., \& Stine, R. A. (1990). Bootstrapping goodness-of-fit measures in structural equation models. Sociological Methods and Research, 21(2), 205-229. http://dx.doi.org/10.1177/0049124192021002004

Breckler, S. J., Olson, J., \& Wiggins, E. (2006). Social psychology alive. Andover, Hampshire: Cenage Learning.

Brock, M. E., Martin, L. E., \& Buckley, M. R. (2013). Time theft in organizations: The development of the time banditry questionnaire. International Journal of Selection and Assessment, 21(3), 309-321. http://dx.doi.org/10.1111/ijsa.12040

Byrne, B. M. (2009). Structural equation modeling with AMOS: Basic concepts, applications, and programming (2nd ed.). New York, NY: Taylor Francis.

Carpenter, J. P. (2007). Punishing free-riders: How group size affects mutual monitoring and the provision of public goods. Games and Economic Behavior, 60(1), 31-51. http://dx.doi.org/10.1016/j.geb.2006.08.011

Ching, G. S., Tsay, W.-R., Hu, Y.-L., \& Hung, C.-H. (2016). Counterproductive work behaviors within academic institutions: A myth or a reality. International Journal of Research Studies in Psychology, 6(1), 1-14. http://dx.doi.org/10.5861/ijrsp.2016.1629

Çınar, O., \& Karcıoğlu, F. (2015). The relationship between cyber loafing and organizational citizenship behavior: A survey study in Erzurum/Turkey. Procedia - Social and Behavioral Sciences, 207(20), 444-453. http://dx.doi.org/10.1016/j.sbspro.2015.10.114

Cohen, L., Manion, L., \& Morrison, K. (2007). Research methods in education. New York: Routledge.

Cornelius, N. (2002). Building workplace equality: Ethics, diversity and inclusion. London: Thomson.

Cronbach, L. J. (1951). Coefficient alpha and the internal structure of tests. Psychometrika, 16, 197-334. http://dx.doi.org/10.1007/BF02310555

Danna, K., \& Griffin, R. W. (1999). Health and well-being in the workplace: A review and synthesis of the literature. Journal of Management, 25(3), 357-384. http://dx.doi.org/10.1177/014920639902500305

Fine, S., Horowitz, I., Weigler, H., \& Basis, L. (2010). Is good character good enough? The effects of situational variables on the relationship between integrity and counterproductive work behaviors. Human Resource Management Review, 20(1), 73-84. http://dx.doi.org/10.1016/j.hrmr.2009.03.010

Fisher, R., \& Katz, J. E. (2000). Social-desirability bias and the validity of self-reported values. Psychology \& Marketing, 17(February), 105-120.

Fornell, C., \& Larcker, D. F. (1981). Evaluating structural equation models with unobservable variables and measurement error. Journal of Marketing Research, 18(1), 39-50. http://dx.doi.org/10.2307/3151312

Fox, S., Spector, P. E., \& Miles, D. (2001). Counterproductive work behavior (CWB) in response to job stressors and organizational justice: Some mediator and moderator tests for autonomy and emotions. Journal of Vocational Behavior, 59(3), 291-309. http://dx.doi.org/10.1006/jvbe.2001.1803

Fox, S., \& Stallworth, L. E. (2010). The battered apple: An application of stressor-emotion-control/support theory to teachers' experience of violence and bullying. Human Relations, 63(7), 927-954. http://dx.doi.org/10.1177/0018726709349518

Furnham, A., \& Taylor, J. (2011). Bad apples: Identify, prevent and manage negative behavior at work. New York, NY: Palgrave Macmillan.

Giacolone, R. A., \& Greenberg, J. (1997). Antisocial behavior in organizations. Thousand Oaks, CA: Sage.

Grawitch, M. J., Gottschalk, M., \& Munz, D. C. (2006). The path to a healthy workplace: A critical review linking healthy workplace practices, employee well-being, and organizational improvements. Consulting Psychology Journal: Practice and Research, 35(3), 129-147. http://dx.doi.org/10.1037/1065-9293.58.3.129

Gruys, M. L., \& Sackett, P. R. (2003). Investigating the dimensionality of counterproductive work behavior. International Journal of Selection and Assessment, 11(1), 30-42. http://dx.doi.org/10.1111/1468-2389.00224

Hair, J. F., Jr., Black, W. C., Babin, B. J., \& Anderson, R. E. (2010). Multivariate data analysis: A global perspective. Upper Saddle, NJ: Pearson.

Hammer, L. B., Bauer, T. N., \& Grandey, A. A. (2003). Work-family conflict and work-related withdrawal behaviors. Journal of Business and Psychology, 17(3), 419-436. http://dx.doi.org/10.1111/10.1023/A:1022820609967

Hu, L. T., \& Bentler, P. M. (1999). Cutoff criteria for fit indexes in covariance structure analysis: Conventional criteria versus new alternatives. Structural Equation Modeling: A Multidisciplinary Journal, 6(1), 1-55. http://dx.doi.org/10.1080/10705519909540118

Hu, Y.-L., Hung, C.-H., \& Ching, G. S. (2015). Examining the counterproductive work behaviors within Taiwan academic setting: A pilot study. Higher Education Evaluation and Development, 9(1), 63-82. 
Hu, Y.-L., Hung, C.-H., \& Ching, G. S.,

http://dx.doi.org/10.6197/HEED.2015.0901.04

Hung, T. K., Chi, N. W., \& Lu, W. L. (2009). Exploring the relationships between perceived coworker loafing and counterproductive work behaviors: The mediating role of a revenge motive. Journal of Business and Psychology, 24(3), 257-270. http://dx.doi.org/10.1007/s10869-009-9104-6

Jones, D. A. (2009). Getting even with one's supervisor and one's organization: Relationships among types of injustice, desires for revenge, and counterproductive work behaviors. Journal of Organizational Behavior, 30(4), 525-542. http://dx.doi.org/10.1002/job.563

Jones, G. E., \& Kavanagh, M. J. (1996). An experimental examination of the effects of individual and situational factors on unethical behavioral intentions in the workplace. Journal of Business Ethics, 15(5), 511-523. http://dx.doi.org/10.1007/BF00381927

Kelly, S. (2008). Social identity theories and educational engagement. British Journal of Sociology of Education, 30(4), 449-462. http://dx.doi.org/10.1080/01425690902954620

Kidwell, R. E. (2010). Loafing in the 21st century: Enhanced opportunities - and remedies - for withholding job effort in the new workplace. Business Horizons, 53(6), 543-552. http://dx.doi.org/10.1016/j.bushor.2010.06.001

Kreuter, F., Presser, S., \& Tourangeau, R. (2008). Social desirability bias in CATI, IVR, and web surveys: The effects of mode and question sensitivity. Public Opinion Quarterly, 72(5), 847-865.

Latané, B., Williams, K., \& Harkins, S. (1979). Many hands make light the work: The causes and consequences of social loafing. Journal of Personality and Social Psychology, 37(6), 822-832. http://dx.doi.org/10.1037/0022-3514.37.6.822

Lazega, E. (2000). Rule enforcement among peers: A lateral control regime. Organization Studies, 21(1), 193-214. http://dx.doi.org/10.1177/0170840600211003

Liden, R. C., Wayne, S. J., Jaworski, R. A., \& Bennett, N. (2004). Social loafing: A field investigation. Journal of Management, 30(2), 285-304. http://dx.doi.org/10.1016/j.jm.2003.02.002

Likert, R. (1932). A technique for the measurement of attitudes. New York: Columbia University Press.

Lim, V. K. G., \& Chen, D. J. Q. (2012). Cyberloafing at the workplace: Gain or drain on work? Behaviour \& Information Technology 31(4), 343-353. http://dx.doi.org/10.1080/01449290903353054

Lim, V. K. G., \& Teo, T. S. H. (2005). Prevalence, perceived seriousness, justification and regulation of cyberloafing in Singapore: An exploratory study. Information \& Management, 42(8), 1081-1093. http://dx.doi.org/10.1016/j.im.2004.12.002

Lumpkin, A. (2008). Teachers as role models teaching character and moral virtues. Journal of Physical Education, Recreation \& Dance, 79(2), 45-50. http://dx.doi.org/10.1080/07303084.2008.10598134

MacKinnon, D. P., \& Dwyer, J. H. (1993). Estimating mediated effects in prevention studies. Evaluation Review, 17(2), 144-158. http://dx.doi.org/10.1177/0193841X9301700202

MacKinnon, D. P., Lockwood, C. M., Hoffman, J. M., West, S. G., \& Sheets, V. (2002). A comparison of methods to test mediation and other intervening variable effects. Psychological Methods, 7(1), 83-104.

Mann, C. J. (2003). Observational research methods. Research design II: Cohort, cross sectional, and case-control studies. Emergency Medicine Journal, 20, 54-60. http://dx.doi.org/10.1136/emj.20.1.54

Marcus, B., Taylor, O. A., Hastings, S. E., Sturm, A., \& Weigelt, O. (2016). The structure of counterproductive work behavior: A review, a structural meta-analysis, and a primary study. Journal of Management, 42(1), 203-233. http://dx.doi.org/10.1177/0149206313503019

Martinko, M. J., Gundlach, M. J., \& Douglas, S. C. (2002). Toward an integrative theory of counterproductive workplace behavior: A causal reasoning perspective. International Journal of Selection and Assessment, 10(1-2), 36-50. http://dx.doi.org/10.1111/1468-2389.00192

Moede, W. (1927). The guidelines of performance psychology [Die richtlinien der leistungs-psychologie]. Industrial Psychotechnics [Industrielle Psychotechnik], 4, 193-207.

Mulvey, P. W., \& Klein, H. J. (1998). The impact of perceived loafing and collective efficacy on group goal processes and group performance. Organizational Behavior and Human Decision Processes, 74(1), $62-87$.

Murphy, S. M., Wayne, S. J., Liden, R. C., \& Erdogan, B. (2003). Understanding social loafing: The role of justice perceptions and exchange relationships. Human Relations, 56(1), 61-84. http://dx.doi.org/10.1177/0018726703056001450

Orr, S. W. (2001). The economics of shame in work groups: How mutual monitoring can decrease cooperation in teams. Kyklos, 54(1), 49-66. http://dx.doi.org/10.1111/1467-6435.00140

Paillé, P., \& Grima, F. (2011). Citizenship and withdrawal in the workplace: Relationship between organizational citizenship behavior, intention to leave current job and intention to leave the organization. The Journal of Social Psychology, 151(4), 478-493. http://dx.doi.org/10.1080/00224545.2010.507266

Peterson, D. K. (2002). Deviant workplace behavior and the organization's ethical climate. Journal of Business 
Monitoring and sanctioning, perceived loafing, revenge motive, and counterproductive work behaviors and Psychology, 17(1), 47-61. http://dx.doi.org/10.1023/A:1016296116093

Price, K. H., Harrison, D. A., \& Gavin, J. H. (2006). Withholding inputs in team contexts: Member composition, interaction processes, evaluation structure, and social loafing. Journal of Applied Psychology, 91(6), 1375-1384. http://dx.doi.org/10.1037/0021-9010.91.6.1375

Reiss, M. C., \& Mitra, K. (1998). The effects of individual difference factors on the acceptability of ethical and unethical workplace behaviors. Journal of Business Ethics, 17(14), 1581-1593. http://dx.doi.org/10.1023/A:1005742408725

Robinson, S. L., \& Bennett, R. J. (1995). A typology of deviant workplace behaviors: A multidimensional scaling study. Academy of Management Journal, 38(2), 555-572.

Sackett, P. R. (2002). The structure of counterproductive work behaviors: Dimensionality and relationships with facets of job performance. International Journal of Selection and Assessment, 10(1-2), 5-11. http://dx.doi.org/10.1111/1468-2389.00189

Salami, S. O. (2010). Job stress and counterproductive work behavior: Negative affectivity as a moderator. The Social Sciences, 5(6), 486-492.

Semmer, N. K., Tschan, F., Meier, L. L., Facchin, S., \& Jacobshagen, N. (2009). Illegitimate tasks and counterproductive work behavior. Applied Psychology, 59(1), 70-96. http://dx.doi.org/10.1111/j.1464-0597.2009.00416.x

Shrout, P. E., \& Bolger, N. (2002). Mediation in experimental and nonexperimental studies: New procedures and recommendations. Psychological Methods, 7(4), 422-445. http://dx.doi.org/10.1037/1082-989X.7.4.422

Skarlicki, D. P., \& Folger, R. (1997). Retaliation in the workplace: The roles of distributive, procedural, and interactional justice. Journal of Applied Psychology, 82(3), 434-443. http://dx.doi.org/10.1037/0021-9010.82.3.434

Sloep, P., Kester, L., Brouns, F., Van Rosmalen, P., De Vries, F., De Croock, M., et al. (2007). Ad hoc transient communities to enhance social interaction and spread tutor responsibilities. In V. Uskov (Ed.), The sixth IASTED international conference on web-based education (pp. 549-554). Calgary, Canada: Acta Press.

Snider, L. (2001). Crimes against capital: Discovring theft of time. Social Justice, 28(3), 105-120.

Sobel, M. E. (1982). Asymptotic intervals for indirect effects in structural equations models. In S. Leinhart (Ed.), Sociological methodology 1982 (pp. 290-312). San Francisco, CA: Jossey-Bass.

Spector, P. E., Fox, S., Penney, L. M., Bruursema, K., Goh, A., \& Kessler, S. (2006). The dimensionality of counterproductivity: Are all counterproductive behaviors created equal? Journal of Vocational Behavior, 68(3), 446-460. http://dx.doi.org/10.1016/j.jvb.2005.10.005

Stone, C. A., \& Sobel, M. E. (1990). The robustness of estimates of total indirect effects in covariance structure models estimated by maximum. Psychometrika, 55(2), 337-352. http://dx.doi.org/10.1007/BF02295291

Sugai, G., \& Horner, R. (2008). The evolution of discipline practices: School-wide positive behavior supports. Child \& Family Behavior Therapy, 24(1-2), 23-50. http://dx.doi.org/10.1300/J019v24n01_03

Sugai, G., \& Horner, R. H. (2009). Responsiveness-to-intervention and school-wide positive behavior supports: Integration of multi-tiered system approaches. Exceptionality, 17(4), 223-237. http://dx.doi.org/10.1080/09362830903235375

Sugai, G., Sprague, J. R., Horner, R. H., \& Walker, H. M. (2000). Preventing school violence: The use of office discipline referrals to assess and monitor school-wide discipline interventions. Journal of Emotional and Behavioral Disorders, 8(2), 94-101. http://dx.doi.org/10.1177/106342660000800205

Sunoo, B. (1996). This employee may be loafing: Can you tell? Should you care? Personnel Journal, 75(12), 54-62.

Tsaw, D., Murphy, S. M., \& Detgen, J. (2011). Social loafing and culture: Does gender matter? International Review of Business Research Papers, 7(3), 1-8.

Tucker, L. R., \& Lewis, C. (1973). A reliability coefficient for maximum likelihood factor analysis. Psychometrika, 38(1), 1-10. http://dx.doi.org/10.1007/BF02291170

Umphress, E. E., Bingham, J. B., \& Mitchell, M. S. (2010). Unethical behavior in the name of the company: The moderating effect of organizational identification and positive reciprocity beliefs on unethical pro-organizational behavior. Journal of Applied Psychology, 95(4), 769-780. http://dx.doi.org/10.1037/a0019214

van de Mortel, T. F. (2008). Faking it: Social desirability response bias in self-report research. Australian Journal of Advanced Nursing, 25(4), 40-48.

Zoghbi-Manrique-de-Lara, P. (2011). Predicting nonlinear effects of monitoring and punishment on employee deviance: The role of procedural justice. European Management Journal, 29(4), 272-282. http://dx.doi.org/10.1016/j.emj.2011.03.003 
Hu, Y.-L., Hung, C.-H., \& Ching, G. S., 